\title{
Lipid Dynamics and Phase Transition within -Synuclein Amyloid Fibrils
}

Galvagnion, Céline; Topgaard, Daniel; Makasewicz, Katarzyna; Buell, Alexander K; Linse, Sara; Sparr, Emma; Dobson, Christopher M

Published in:

Journal of Physical Chemistry Letters

Link to article, DOI:

10.1021/acs.jpclett.9b03005

Publication date:

2019

Document Version

Publisher's PDF, also known as Version of record

Link back to DTU Orbit

Citation (APA):

Galvagnion, C., Topgaard, D., Makasewicz, K., Buell, A. K., Linse, S., Sparr, E., \& Dobson, C. M. (2019). Lipid Dynamics and Phase Transition within -Synuclein Amyloid Fibrils. Journal of Physical Chemistry Letters, 10, 7872-7877. https://doi.org/10.1021/acs.jpclett.9b03005

\section{General rights}

Copyright and moral rights for the publications made accessible in the public portal are retained by the authors and/or other copyright owners and it is a condition of accessing publications that users recognise and abide by the legal requirements associated with these rights.

- Users may download and print one copy of any publication from the public portal for the purpose of private study or research.

- You may not further distribute the material or use it for any profit-making activity or commercial gain

- You may freely distribute the URL identifying the publication in the public portal 


\section{Lipid Dynamics and Phase Transition within $\alpha$-Synuclein Amyloid Fibrils}

Céline Galvagnion, ${ }^{* \dagger, \ddagger, \Phi[\odot ~ D a n i e l ~ T o p g a a r d, ~}{ }^{\S}$ Katarzyna Makasewicz, ${ }^{\S}$ Alexander K. Buell, ${ }^{\| \odot}$ Sara Linse, ${ }^{\perp}{ }^{\mathbb{O}}$ Emma Sparr, ${ }^{\S}$ and Christopher M. Dobson ${ }^{\dagger, \#}$

${ }^{\dagger}$ Centre for Misfolding Diseases, Department of Chemistry, University of Cambridge, Lensfield Road, Cambridge CB2 1EW, United Kingdom

${ }^{\ddagger}$ German Center for Neurodegenerative Diseases, Sigmund-Freud-Str. 27, 53127 Bonn,Germany

${ }^{\S}$ Division of Physical Chemistry, Center for Chemistry and Chemical Engineering, Lund University, P.O. Box 124, SE-22100 Lund, Sweden

"Department of Biotechnology and Biomedicine, DTU Bioengineering, Technical University of Denmark, Soltofts Plads 227, DK-2800 Kgs. Lyngby, Denmark

${ }^{\perp}$ Department of Biochemistry and Structural Biology, Lund University, SE-22100 Lund, Sweden

\section{Supporting Information}

ABSTRACT: The deposition of coassemblies made of the small presynaptic protein, $\alpha$-synuclein, and lipids in the brains of patients is the hallmark of Parkinson's disease. In this study, we used natural abundance ${ }^{13} \mathrm{C}$ and ${ }^{31} \mathrm{P}$ magic-angle spinning nuclear magnetic resonance spectroscopy together with cryo-electron microscopy and differential scanning calorimetry to characterize the fibrils formed by $\alpha$-synuclein in the presence of vesicles made of 1,2-dimyristoyl-sn-glycero-3-phospho-Lserine or 1,2-dilauroyl-sn-glycero-3-phospho-L-serine. Our results show that these lipids coassemble with $\alpha$-synuclein molecules to give thin and curly amyloid fibrils. The coassembly leads to slower and more isotropic

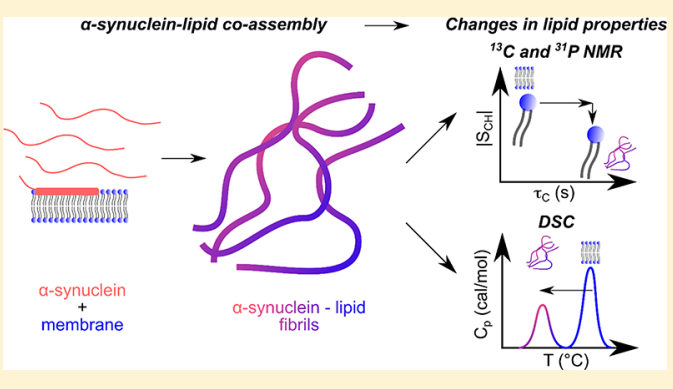
reorientation of lipid molecular segments and a decrease in both the temperature and enthalpy of the lipid chain-melting compared with those in the protein-free lipid lamellar phase. These findings provide new insights into the properties of lipids within protein-lipid assemblies that can be associated with Parkinson's disease.

$\mathrm{P}$ arkinson's disease (PD) is characterized by the presence in the brains of patients of protein deposits known as Lewy bodies (LBs). ${ }^{1}$ LBs are mainly composed of the small presynaptic protein, $\alpha$-synuclein, ${ }^{1}$ but they can also contain other molecules, including ubiquitin and lipids. ${ }^{2,3}$ The process by which different molecules coassemble with $\alpha$-synuclein to form LBs is not yet understood. Protein-lipid coassemblies, in the form of lipoprotein particles or fibrils, have been reported for systems including $\alpha$-synuclein, ${ }^{4-6}$ apolipoprotein $\mathrm{A1},{ }^{7}$ and islet amyloid polypeptide. ${ }^{8,9}$ In particular, lipid molecules (i.e., 1,2-dioleoyl-sn-glycero-3-phospho-L-choline (DOPC) and 1,2dioleoyl-sn-glycero-3-phospho-L-serine (DOPS)) have been found to coassemble with $\alpha$-synuclein to form protein-lipid amyloid fibril. ${ }^{6}$ Moreover, the characterization of the fibrils formed in the presence of DOPS/DOPC-containing bilayers using natural abundance ${ }^{13} \mathrm{C}$ magic-angle spinning nuclear magnetic resonance (MAS NMR) spectroscopy ${ }^{10}$ showed that the lipid molecules within these fibrils are more rigid than those in the protein-free lipid lamellar phase. ${ }^{6}$

The presence of small unilamellar vesicles composed of 1,2dimyristoyl-sn-glycero-3-phospho-L-serine (DMPS) or 1,2dilauroyl-sn-glycero-3-phospho-L-serine (DLPS) has been found to induce the formation of kinetically trapped $\alpha$ - synuclein proto-fibrils. ${ }^{11,12}$ The term proto-fibrils has been used to describe these structures as they are observed to be thinner $\left(\sim 5 \mathrm{~nm}\right.$ in thickness $\left.{ }^{11}\right)$ and curlier than the mature fibrils formed by $\alpha$-synuclein in the absence of lipids. ${ }^{13,14}$ Moreover, these proto-fibrils were found to be able to convert into mature fibrils through an increase in temperature. ${ }^{15}$ Finally, the concentration of $\alpha$-synuclein lipid-induced protofibrils formed in these experiments was found to be proportional to the concentration of the lipids (DMPS and DLPS) ([fibrils $] \sim 0.1[$ lipids $]$ ), ${ }^{12}$ suggesting that lipids may not only be involved in the initial steps of the reaction resulting in amyloid formation ${ }^{11}$ but also act as reactants in this process.

In this study, we used ${ }^{13} \mathrm{C}$ and ${ }^{31} \mathrm{P}$ MAS NMR, differential scanning calorimetry (DSC), and cryo-electron microscopy (cryo-EM) to characterize the proto-fibrils formed by $\alpha$ synuclein in the presence of DMPS and DLPS vesicles under quiescent conditions at $30{ }^{\circ} \mathrm{C}$ for $4 \mathrm{~d}$ (see Methods in the Supporting Information and refs 11 and 12 for more details). Cryo-EM images show that $\alpha$-synuclein forms thin and curly

Received: October 14, 2019

Accepted: December 2, 2019

Published: December 2, 2019 

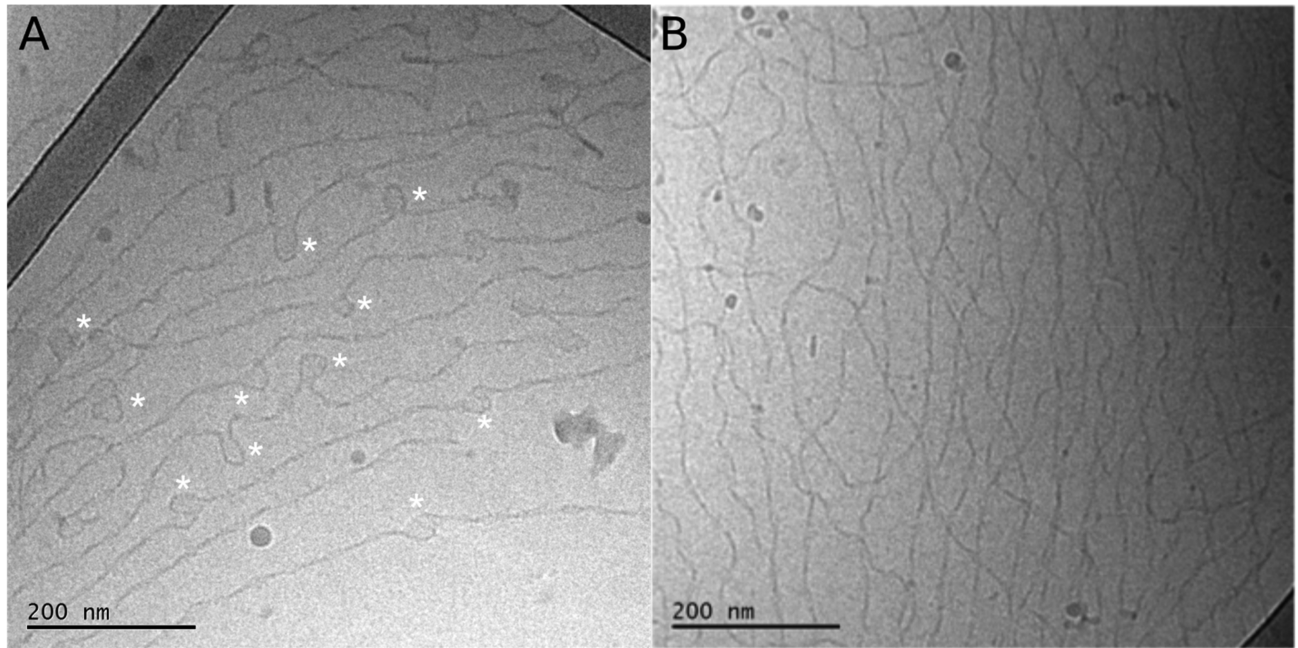

Figure 1. Cryo-EM images of proto-fibrils formed by $\alpha$-synuclein in the presence of DMPS and DLPS vesicles. The proto-fibrils were formed after mixing $50 \mu \mathrm{M}$ monomeric $\alpha$-synuclein with $100 \mu \mathrm{M}$ DMPS (A) or DLPS (B) dispersed as small unilamellar vesicles in phosphate buffer at pH 6.5 and $30{ }^{\circ} \mathrm{C}$ and incubating this mixture for $4 \mathrm{~d}$ under quiescent conditions (see Methods in the Supporting Information for more details).

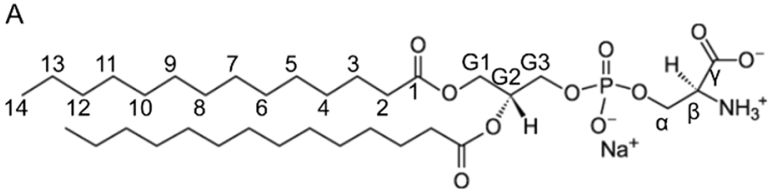
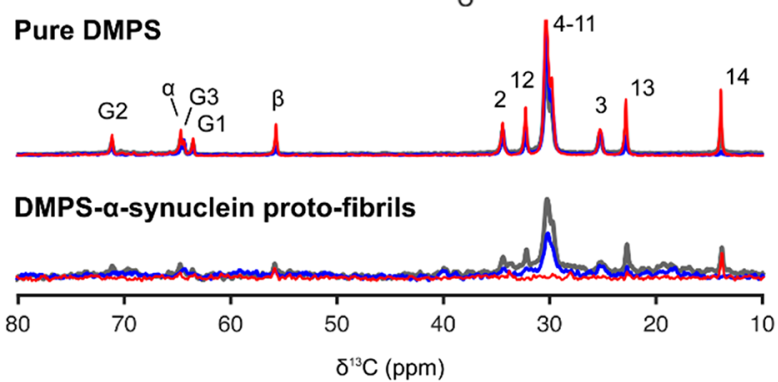

C Pure DMPS, $60^{\circ} \mathrm{C}$

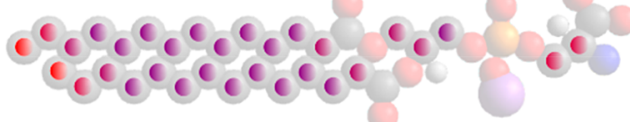

DMPS- $\alpha$-synuclein proto-fibrils, $60^{\circ} \mathrm{C}$

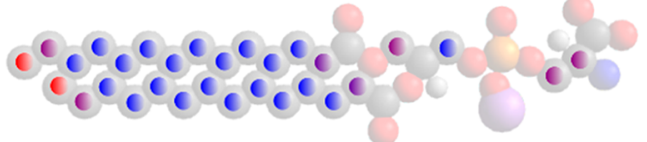

B

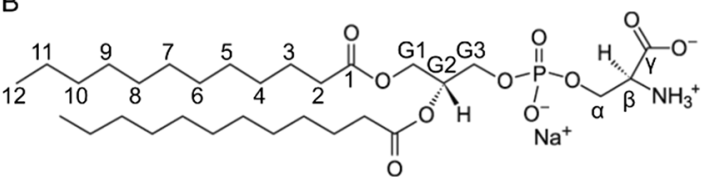

Pure DLPS

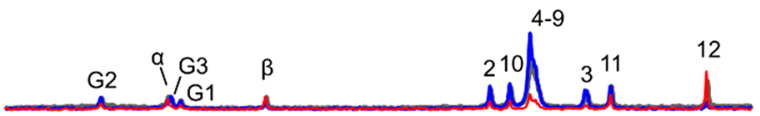

DLPS- $\alpha-s y n u c l e i n$ proto-fibrils

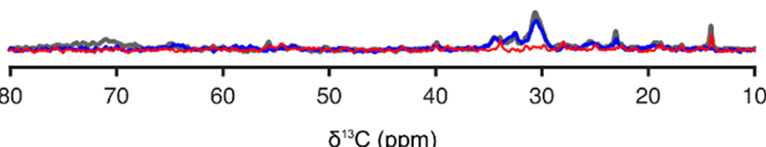

D Pure DLPS, $30^{\circ} \mathrm{C}$

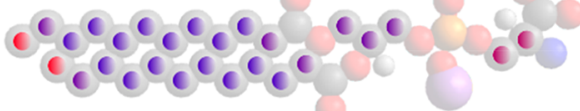

DLPS-a-synuclein proto-fibrils, $30^{\circ} \mathrm{C}$

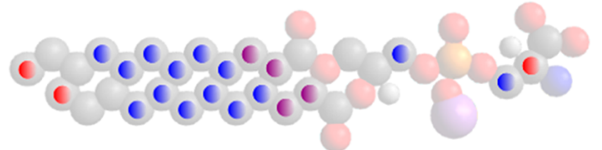

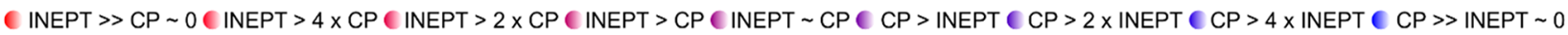

Figure 2. ${ }^{13} \mathrm{C}$ MAS NMR spectra and dynamics of DMPS and DLPS in the pure lipid systems and within $\alpha$-synuclein proto-fibrils. (A and B) ${ }^{13} \mathrm{C}$ CP-DP-INEPT MAS NMR spectra of the pure lipid systems (top) and of lipid-induced $\alpha$-synuclein proto-fibrils (bottom) (A, DMPS; B, DLPS) measured at 60 (A) or $30^{\circ} \mathrm{C}$ (B), respectively. The molecular structure of DMPS (A) and DLPS (B) molecules and the assignment of the resonances of their carbon atoms are shown above the corresponding set of spectra. ${ }^{13} \mathrm{C}$ INEPT, CP, and DP MAS NMR spectra are shown in red, blue, and gray, respectively. The proto-fibrils were formed after mixing $100 \mu \mathrm{M}$ monomeric $\alpha$-synuclein with 2 mM DMPS (A) or DLPS (B) dispersed as small unilamellar vesicles in phosphate buffer at $\mathrm{pH} 6.5$ and $30{ }^{\circ} \mathrm{C}$ and incubating this mixture for $4 \mathrm{~d}$ under quiescent conditions. (C and D) Relative intensities from the INEPT and CP experiments for the pure lipid systems (top) or for the lipids incorporated within $\alpha$-synuclein proto-fibrils (bottom) at $60{ }^{\circ} \mathrm{C}$ for DMPS or $30^{\circ} \mathrm{C}$ for DLPS. The ratio $\frac{I_{\mathrm{INEPT}}}{I_{\mathrm{CP}}}$ depends on both the correlation time, $\tau_{\mathrm{C}}$, and the order parameter, $\mathrm{I}$ $\mathrm{S}_{\mathrm{CH}} \mathrm{l}$, for the $\mathrm{C}-\mathrm{H}$ bond vector in the molecular segment; the relative value for each carbon atom is displayed using the color scheme shown at the bottom of the figure.

fibrils in bulk solution under these conditions (Figures 1A,B and S1), an observation in agreement with images of these fibrils acquired using atomic force microscopy and electron microscopy on dried samples. ${ }^{11,12,16}$ 

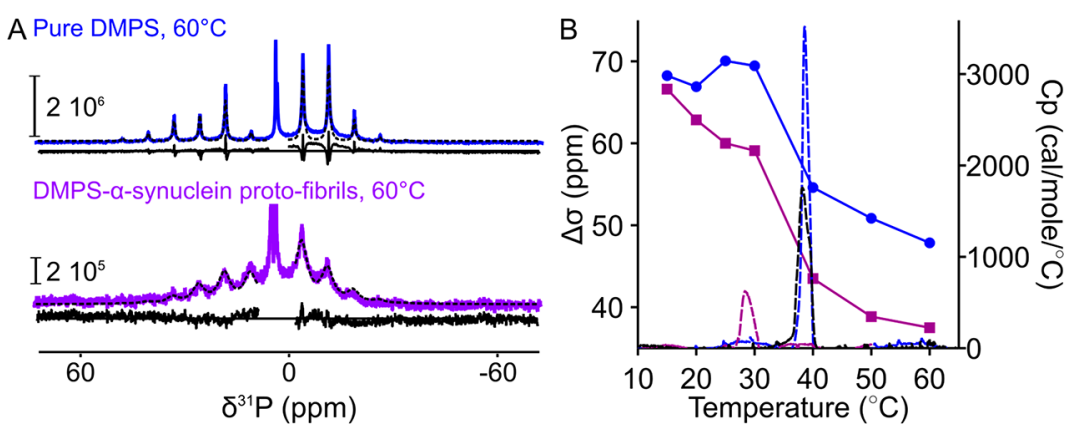

Figure 3. ${ }^{31} \mathrm{P}$ MAS NMR spectra, chemical shift anisotropy, and DSC thermograms of DMPS in the pure lipid system and within $\alpha$-synuclein proto-fibrils. (A) ${ }^{31} \mathrm{P}$ MAS NMR spectra at spinning rate $=1250 \mathrm{~Hz}$ of pure DMPS (top) and DMPS-induced $\alpha$-synuclein proto-fibrils (bottom) measured at $60{ }^{\circ} \mathrm{C}$. The experimental data are shown as continuous lines; the fits are shown as dotted black lines, and the residuals of the fits are shown underneath each spectrum. (B) Combined results from ${ }^{31}$ P MAS NMR and DSC measurements for DMPS in the pure lipid system and within $\alpha$-synuclein proto-fibrils at varying temperatures. Left $y$-axis: Change in the ${ }^{31} \mathrm{P} \Delta \sigma$ of the pure DMPS (blue circles) and DMPS-induced $\alpha$ synuclein proto-fibrils (purple squares) with increasing temperatures. Right $y$-axis: Change in the molar heat capacity (Cp) of DMPS solubilized as vesicles (blue dashed line) or of DMPS-induced $\alpha$-synuclein proto-fibrils untreated (purple dashed line) or treated with proteinase-K (black dashed line) with increasing temperatures. The chain melting enthalpies were found to be ca. 25 (pure lipid system, blue dashed line), ca. $6 \mathrm{~kJ}^{\mathrm{mol}}{ }^{-1}$ (DMPS-induced $\alpha$-synuclein proto-fibrils, purple dashed line) and ca. $17 \mathrm{~kJ} \mathrm{~mol}^{-1}$ (proteinase-K treated DMPS-induced $\alpha$-synuclein proto-fibrils, black dashed line).

These thin and curly assemblies may therefore be called proto-fibrils, consistently with the nomenclature used for these assemblies described in our previous studies. ${ }^{11,12,15,16}$ The cryo-EM images of the DMPS-induced $\alpha$-synuclein protofibrils are characterized by the presence of spherical structures that appear to either be opened or closed (indicated with star symbols on Figure 1A). We attributed these structures to either loops in the proto-fibrils or remaining vesicles. Finally, the morphology of these proto-fibrils is very different from that of mature fibrils formed by $\alpha$-synuclein alone; the latter were found to be thicker and straighter than the proto-fibrils and to be organized as parallel bundles using cryo-EM. ${ }^{6}$ We then used natural abundance ${ }^{13} \mathrm{C}$ MAS NMR to investigate whether lipid molecules are incorporated within the proto-fibrils. We first acquired ${ }^{13} \mathrm{C}$ MAS NMR spectra of the protein-free lipid lamellar phase, where lipid molecules, DMPS or DLPS, are organized as multilayer stacks of bilayers (Figure 2A (DMPS) and B (DLPS), gray spectra). These reference samples will be referred to as "pure lipid system" throughout the rest of the Letter. The ${ }^{13} \mathrm{C}$ MAS NMR spectra of the pure lipid systems were measured at temperatures above the melting temperature $\left(\mathrm{T}_{\mathrm{m}}\right)$ of the lipids, at $60^{\circ} \mathrm{C}$ for DMPS $\left(\mathrm{T}_{\mathrm{m}} \approx 39^{\circ} \mathrm{C}\right)$ and 30 ${ }^{\circ} \mathrm{C}$ for DLPS $\left(\mathrm{T}_{\mathrm{m}} \approx 20{ }^{\circ} \mathrm{C}\right)$, and were used as references for the DMPS or DLPS bilayers in the fluid phase. We then acquired ${ }^{13} \mathrm{C}$ MAS NMR spectra of DMPS- and DLPS-induced $\alpha$-synuclein proto-fibrils at these temperatures, and we observed the presence of ${ }^{13} \mathrm{C}$ resonances from the different lipid carbons (Figure 2A (DMPS) and B (DLPS), gray spectra), implying that DMPS and DLPS coassemble with $\alpha$ synuclein into proto-fibrils.

To get insight into the molecular dynamics of DMPS and DLPS within $\alpha$-synuclein proto-fibrils, we then used polarization transfer ${ }^{13} \mathrm{C}$ MAS NMR. ${ }^{10}$ Indeed, it is possible to obtain qualitative site-specific information about the molecular mobility of each lipid carbon from the experimental data by comparing the intensities of each of the cross-polarization $(\mathrm{CP})$, direct polarization (DP), and insensitive nuclei enhanced by polarization transfer (INEPT) signals. The signal intensity of a given carbon in an INEPT and a CP spectrum, $\mathrm{I}_{\mathrm{INEPT}}$ and $\mathrm{I}_{\mathrm{CP}}$, respectively, depends on the correlation time $\left(\tau_{\mathrm{C}}\right)$ and the order parameter $\left(\left|\mathrm{S}_{\mathrm{CH}}\right|\right)$ for the $\mathrm{C}-\mathrm{H}$ bond vector in the molecular segment. ${ }^{10}$ In the $\mathrm{CP}$ experiment, polarization is transferred from ${ }^{1} \mathrm{H}$ to ${ }^{13} \mathrm{C}$ via through-space dipolar couplings, which are averaged to zero by fast isotropic reorientation. Therefore, $\mathrm{CP}$ spectra are expected to yield maximal signals for rigid segments, with $\tau_{\mathrm{C}}>10 \mu \mathrm{s}$ and/or I $\mathrm{S}_{\mathrm{CH}} \mathrm{I}>0.5 .^{10}$ In an INEPT experiment, polarization is transferred from ${ }^{1} \mathrm{H}$ to ${ }^{13} \mathrm{C}$ through covalent bonds and will show a signal as long as the ${ }^{1} \mathrm{H}$ and ${ }^{13} \mathrm{C}$ transverse relaxation times are longer than the time required for ${ }^{1} \mathrm{H}-{ }^{13} \mathrm{C}$ polarization transfer. ${ }^{10}$ INEPT spectra will yield intense signals for mobile segments with $\tau_{\mathrm{C}}<0.01 \mu \mathrm{s}$ and $\left|\mathrm{S}_{\mathrm{CH}}\right|<0.05 .{ }^{10} \mathrm{We}$ acquired sets of ${ }^{13} \mathrm{C}$ CP-DP-INEPT MAS spectra of the DMPS- and DLPS-induced $\alpha$-synuclein proto-fibrils that we compared to those of the pure lipid system samples (Figure $2 \mathrm{~A}, \mathrm{~B})$ at 60 and $30^{\circ} \mathrm{C}$, respectively. At these temperatures, the DMPS and DLPS bilayers in the pure lipid system are in the fluid phase, as illustrated by the presence of all the resonances of the different ${ }^{13} \mathrm{C}$ on their respective INEPT spectra (red spectra Figure 2A (DMPS) and B (DLPS)). In the case of DMPS- and DLPS-induced $\alpha$-synuclein proto-fibrils, we observed only the resonances corresponding to the carbons $\mathrm{C}_{\alpha}, \mathrm{C}_{\beta}$ of the polar head, $\mathrm{C}_{\mathrm{G}_{1}}$ of the glycerol group, and the carbons of the end methyl ( $\mathrm{C}_{14}$ for DMPS (Figure 2A) and $\mathrm{C}_{12}$ of DLPS (Figure $2 \mathrm{~B})$ ) of the lipids on their respective INEPT spectrum. We compared the relative intensities ( $\mathrm{I}_{\mathrm{DP}}, \mathrm{I}_{\mathrm{INEPT}}$, and $\mathrm{I}_{\mathrm{CP}}$ ) for the different carbons of DMPS and DLPS in the proto-fibrils to those in the pure lipid system, and we found that all carbons, except the end methyls, have a lower reorientation rate (increase of $\tau_{\mathrm{C}}$ ) and/or a more anisotropic reorientation (increase of $\left|S_{\mathrm{CH}}\right|$ ) after coassembly with $\alpha$ synuclein into amyloid proto-fibrils (Figure 2C,D). Interestingly, the relative intensities $\left(\mathrm{I}_{\mathrm{DP}}, \mathrm{I}_{\mathrm{INEPT}}\right.$, and $\left.\mathrm{I}_{\mathrm{CP}}\right)$ of the end methyl $\mathrm{C}_{12}$ DLPS or $\mathrm{C}_{14}$ DMPS suggested that $\tau_{\mathrm{C}}<0.01 \mu \mathrm{s}$ and $\left|S_{\mathrm{CH}}\right|<0.05$ and that these carbon atoms have a high reorientation rate and a highly isotropic reorientation in both the pure lipid system and in the proto-fibrils (Figure 2C,D).

We then used ${ }^{31} \mathrm{P}$ MAS NMR in order to determine the influence of protein-lipid coassembly into amyloid fibrils on the rate or the anisotropy of the reorientation of the lipid phosphate groups. In particular, we determined the value of the ${ }^{31} \mathrm{P}$ chemical shift anisotropy $(\Delta \sigma)$ of lipid molecules in the 
pure lipid system or in the $\alpha$-synuclein proto-fibrils (Figures 3 and S2) by spectral deconvolution and by fitting the spinning sideband amplitudes of the ${ }^{31} \mathrm{P}$ MAS NMR spectra using the Herzfeld-Berger method of sideband analysis ${ }^{17}$ (Figure 3A). In the case of DMPS, we observed that the ${ }^{31} \mathrm{P}$ MAS NMR line widths of the lipids were larger in the proto-fibrils than in the pure lipid system (Figure $3 \mathrm{~A}$ ) at $60{ }^{\circ} \mathrm{C}$, suggesting that the lipid-protein coassembly leads to a decrease in the rate of reorientation of the DMPS phosphate group. Moreover, the values of ${ }^{31} \mathrm{P} \Delta \sigma$ were found to be ca. $8 \mathrm{ppm}$ lower for DMPS in the proto-fibrils $(40 \mathrm{ppm})$ compared to those in the pure lipid system (48 ppm). This observation implies that the coassembly of DMPS molecules with $\alpha$-synuclein into amyloid fibrils induces a more isotropic reorientation of the phosphate group. In the case of DLPS and DLPS-induced $\alpha$-synuclein proto-fibrils, we observed very broad sidebands that could not be fitted accurately (Figure S2). The broadening of these lines is likely due to the fact that the reorientation of the DLPS phosphate group is on the same time scale as the magic-angle spinning $\left(\tau_{\mathrm{C}} \approx 1 \mathrm{~ms}\right) \cdot{ }^{18,19}$ Altogether, the ${ }^{13} \mathrm{C}$ and ${ }^{31} \mathrm{P}$ MAS NMR measurements show that the coassembly of DMPS and DLPS molecules with $\alpha$-synuclein into amyloid proto-fibrils decreases the rate and the anisotropy of their reorientation (see illustration in Figure 4).

Finally, we investigated the dynamics of DMPS molecules in the pure lipid system and in the DMPS-induced $\alpha$-synuclein proto-fibrils at temperatures ranging from 25 to $60{ }^{\circ} \mathrm{C}$ (Figures 3 and 5). This temperature range spans values below and above the melting temperature of pure DMPS, i.e., ca. $39^{\circ} \mathrm{C} .{ }^{12}$ We used the spectra of pure DMPS measured at 25 and $60^{\circ} \mathrm{C}$ as references for the bilayer in the gel (solid) and fluid phases, respectively. At $25{ }^{\circ} \mathrm{C}$, the broad peak corresponding to the unresolved resonances of the acyl $C_{4}-C_{11}$ carbons $\left(C_{4}-C_{11}\right.$ peak) was found to be centered at $33 \mathrm{ppm}$ for both the pure lipid system and the protein-lipid proto-fibrils. This chemical shift value is characteristic of hydrocarbon chains in an all-trans conformation. ${ }^{23-26}$ Moreover, we observed that the line width of this peak for DMPS was larger in the proto-fibrils than in the pure lipid system. This observation suggests that the $C_{4}-C_{11}$ carbon chains of DMPS sample a wider range of conformations in the proto-fibrils than in the pure lipid system. When the temperature was gradually increased to $60{ }^{\circ} \mathrm{C}$, we observed a decrease in the intensity of the $\mathrm{C}_{4}-\mathrm{C}_{11}$ peak and an increase in the intensity of a new peak at $30 \mathrm{ppm}$ for both the pure lipid system and the protein-lipid proto-fibrils. The chemical shift value of this new peak is characteristic of rapid trans-gauche isomerization of the acyl chains (Figure 5). This result shows that the DMPS acyl chains undergo a conformational change from all-trans $\left(\mathrm{C}_{4}-\mathrm{C}_{11}\right.$ resonances centered at $\left.33 \mathrm{ppm}\right)$ to trans-gauche $\left(\mathrm{C}_{4}-\mathrm{C}_{11}\right.$ resonances centered at $\left.30 \mathrm{ppm}\right)$ as a result of the chain-melting in both the pure lipid system and the DMPS- $\alpha$-synuclein proto-fibrils. ${ }^{27}$ We further investigated the chain-melting behavior of DMPS in the pure lipid system or in $\alpha$-synuclein proto-fibrils using differential scanning calorimetry (DSC) and ${ }^{31} \mathrm{P} \Delta \sigma$ measurements (Figure 3). When the temperature increased from 30 to $60{ }^{\circ} \mathrm{C}$, we observed a sharp decrease in the value of the ${ }^{31} \mathrm{P} \Delta \sigma$ for DMPS in the pure lipid sample, from ca. 68 to ca. $48 \mathrm{ppm}$. This decrease in ${ }^{31} \mathrm{P} \Delta \sigma$ suggests that the phosphate group samples a wider range of orientations with respect to the bilayer normal in the fluid phase. A similar decrease in ${ }^{31} \mathrm{P} \Delta \sigma$ with temperature was observed for DMPS molecules within the $\alpha$-synuclein proto-fibrils, although this transition is less sharp

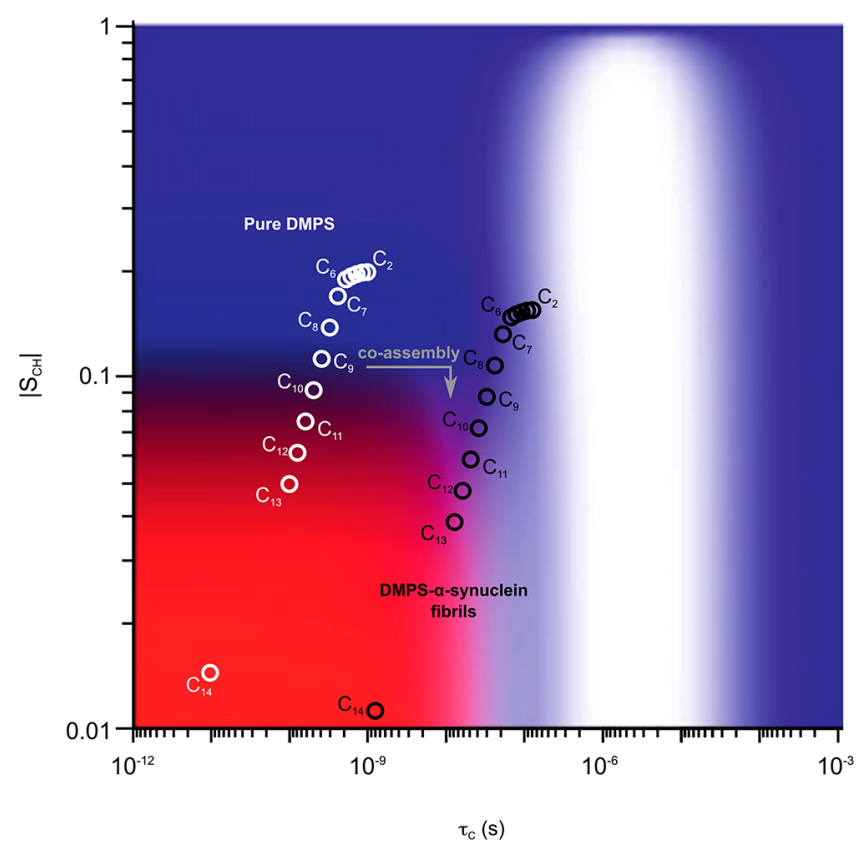

Figure 4. Illustration of the influence of the coassembly of DMPS and $\alpha$-synuclein within proto-fibrils on the lipid dynamics measured at 60 ${ }^{\circ} \mathrm{C}$. Theoretical ${ }^{1} \mathrm{H}-{ }^{13} \mathrm{C}$ polarization transfer efficiency as a function of $\tau_{\mathrm{C}}$ and $\left|\mathrm{S}_{\mathrm{CH}}\right|$ for a $\mathrm{CH}_{2}$ segment at the magnetic field $11.7 \mathrm{~T}$ and the magic-angle spinning frequency $5 \mathrm{kHz}$ (adapted from ref 20 with permission; copyright 2013 Elsevier). The map is color-coded according to the calculated CP (blue) and INEPT (red) intensities. White indicates the absence of signal for both CP and INEPT. Each circle corresponds to a carbon of the acyl chain $\left(\mathrm{C}_{2}-\mathrm{C}_{14}\right)$ of DMPS in the pure lipid system (white open circles) or in the protein-lipid proto-fibrils (black open circles). The position of the carbons results from the estimations of $\tau_{\mathrm{C}}$ and $\left|\mathrm{S}_{\mathrm{CH}}\right|$ that are based on previous quantitative measurements of those parameters ${ }^{21,22}$ (Pure DMPS: I $\mathrm{S}_{\mathrm{CH}} \mathrm{I}\left(\mathrm{C}_{2}-\mathrm{C}_{6}\right) \approx 0.2, \mathrm{IS}_{\mathrm{CH}} \mathrm{I}\left(\mathrm{C}_{6}-\mathrm{C}_{13}\right): 0.2$ to $0.05, \mathrm{IS}_{\mathrm{CH}} \mathrm{I}\left(\mathrm{C}_{14}\right) \approx 0.01$, $\tau_{\mathrm{C}}\left(\mathrm{C}_{2}-\mathrm{C}_{13}\right): 1-0.1 \mathrm{~ns}, \tau_{\mathrm{C}}\left(\mathrm{C}_{14}\right) \approx 0.01 \mathrm{~ns}$; DMPS in $\alpha$-synuclein proto-fibrils: $\tau_{\mathrm{C}}$ increased for all carbons by approximately a factor of $100,{ }^{21,22}$ and $\left|S_{\mathrm{CH}}\right|$ decreased for all carbons by a factor of $\sim 1.3$ (see Figure 3B)).

and occurs at a lower temperature (ca. $29^{\circ} \mathrm{C}$ ) (Figure 3B). The DSC thermograms of DMPS dispersed as vesicles and of DMPS-induced $\alpha$-synuclein proto-fibrils were characterized by the presence of one transition centered at 39 and $29{ }^{\circ} \mathrm{C}$ (Figure 3B), respectively. This observation suggests that the changes in DMPS ${ }^{31} \mathrm{P} \Delta \sigma$ occur at the same temperature as that of the chain-melting transition (ca. $39{ }^{\circ} \mathrm{C}$ for the pure DMPS and ca. $29{ }^{\circ} \mathrm{C}$ for DMPS in the $\alpha$-synuclein protofibrils) (Figure 3B). Moreover, the enthalpy of DMPS chainmelting was found to be ca. four times smaller in the protofibrils than in the pure lipid system. The decrease in the chainmelting enthalpy of DMPS associated with protein-lipid coassembly is likely due to the fact that lipid molecules are less ordered in the proto-fibrils than in the pure lipid system at low temperatures and more rigid in the proto-fibrils than in the pure lipid system at high temperatures (Figure 5). We then investigated whether the observed change in the chain-melting transition of DMPS associated with the protein-lipid coassembly could be reversed by measuring the DSC thermograms of the DMPS-induced $\alpha$-synuclein proto-fibrils after incubation with proteinase-K. The thermogram of the digested proto-fibrils is characterized by the presence of a broader transition centered at ca. $39{ }^{\circ} \mathrm{C}$ and with a transition 


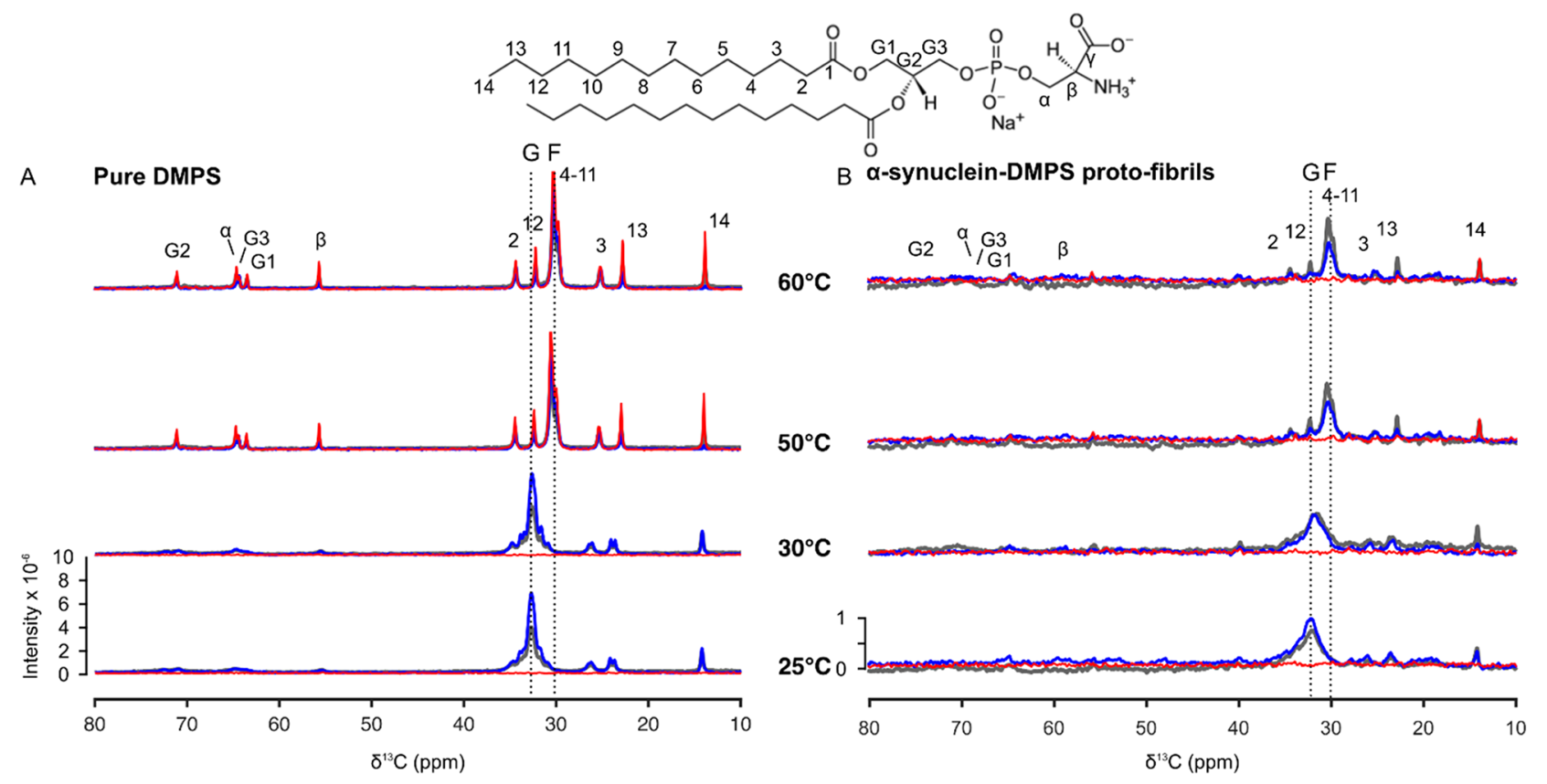

Figure 5. ${ }^{13} \mathrm{C}$ MAS NMR spectra of DMPS in pure lipid systems and within $\alpha$-synuclein proto-fibrils at different temperatures. (A and B) ${ }^{13} \mathrm{C} \mathrm{CP}$ DP-INEPT MAS NMR spectra of the pure DMPS (A) or DMPS-induced $\alpha$-synuclein proto-fibrils (B) measured at increasing temperatures encompassing the melting temperature of DMPS bilayer $\left(\mathrm{T}_{\mathrm{m}} \approx 39^{\circ} \mathrm{C}^{12}\right)$. The molecular structure of DMPS molecules as well as the assignment of the resonances of their carbon atoms are shown above the corresponding set of spectra. ${ }^{13} \mathrm{C}$ INEPT, CP, and DP MAS NMR spectra are shown in red, blue, and gray, respectively. The dotted lines labeled G (gel) and F (fluid) indicate the chemical shift of the unresolved resonances of the acyl $\mathrm{C}_{4}-\mathrm{C}_{11}$ carbons when the lipid chains adopt all-trans or trans-gauche conformation, respectively.

enthalpy equal to ca. $70 \%$ of that of DMPS in the pure lipid system. These results suggest that most of the DMPS molecules are released from the proto-fibrils after proteinase$\mathrm{K}$ treatment and confirm that lipid molecules are present within these structures. Taken together, these results show that the reduced melting temperature and melting enthalpy of DMPS is related to the lipid-protein interaction in the amyloid proto-fibrils and not to a potential loss of lipids and that this process is partly reversible.

In conclusion, the results described in this study show that DMPS and DLPS lipid molecules can coassemble with $\alpha$ synuclein molecules in the formation of proto-fibrils. From the present data we cannot distinguish the location and organization of lipids in the proto-filaments, i.e. whether lipids are incorporated within the fibril structure as individual molecules or as distorted vesicles/membranes. However, our data clearly imply strong lipid-protein interactions in the coassemblies. In particular, our combined ${ }^{13} \mathrm{C},{ }^{31} \mathrm{P}$ MAS NMR, and DSC data indicates that this protein-lipid coassembly was found not only to influence the lipid dynamics by decreasing the rate and the anisotropy of the orientation of their hydrocarbon chains and phosphate groups but also to affect the lipid chain-melting by decreasing both its temperature and enthalpy. These results contribute to a better understanding of the properties of lipid molecules within protein-lipid assemblies such as those found in the brain of patients with Parkinson's disease.

\section{ASSOCIATED CONTENT}

\section{S Supporting Information}

The Supporting Information is available free of charge at https://pubs.acs.org/doi/10.1021/acs.jpclett.9b03005.
Materials and Methods, cryo-EM images of proto-fibrils formed by $\alpha$-synuclein in the presence of DLPS and DMPS vesicles (Figure S1), and ${ }^{31} \mathrm{P}$ MAS NMR spectra of pure DLPS/DMPS and DLPS/DMPS-induced $\alpha$ synuclein proto-fibrils measured at different temperatures (Figure S2) (PDF)

\section{AUTHOR INFORMATION}

\section{Corresponding Author}

*E-mail: celine.galvagnion@sund.ku.dk.

ORCID $\odot$

Céline Galvagnion: 0000-0001-9753-3310

Alexander K. Buell: 0000-0003-1161-3622

Sara Linse: 0000-0001-9629-7109

\section{Present Address}

II C.G.: Department of Drug Design and Pharmacology, Faculty of Health and Medical Sciences, University of Copenhagen, 2100 Copenhagen, Denmark.

\section{Notes}

The authors declare no competing financial interest.

\#C.M.D.: Deceased September 8, 2019.

\section{ACKNOWLEDGMENTS}

This work was supported by a Marie Skłodowska-Curie Actions-Individual Fellowship (H2020-MSCA grant agreement No 706551) (C.G.), the European Soft Matter Infrastructure program (C.G.), the Lundbeck Foundation (C.G.), the Swedish Research Council (2014-07497, 2015-00142) and the Knut and Alice Wallenberg Foundation (E.S., S.L., and D.T.), the Cambridge Centre for Misfolding Diseases (C.G. and C.M.D.), the UK Biotechnology and Biochemical Sciences Research Council (C.M.D.), and the Wellcome Trust 
(C.M.D.). A.K.B. thanks the Novo Nordisk Foundation for support through a Novo Nordisk Foundation Professorship. The authors thank Quoc Dat Pham and Jenny Marie Andersson for technical assistance with rotor preparation and data plotting; Gunnel Karlsson at the Biomicroscopy Unit, Polymer and Materials Chemistry, Chemical Centre, Lund University, Lund, Sweden for assistance with the cryo-EM imaging; and Göran Carlström for his assistance with the acquisition of the MAS NMR experiments.

\section{REFERENCES}

(1) Spillantini, M. G.; Schmidt, M. L.; Lee, V. M.; Trojanowski, J. Q.; Jakes, R.; Goedert, M. Alpha-synuclein in Lewy bodies. Nature 1997, 388, 839-40.

(2) Gai, W. P.; Yuan, H. X.; Li, X. Q.; Power, J. T.; Blumbergs, P. C.; Jensen, P. H. In situ and in vitro study of colocalization and segregation of alpha-synuclein, ubiquitin, and lipids in Lewy bodies. Exp. Neurol. 2000, 166, 324-33.

(3) Wakabayashi, K.; Tanji, K.; Odagiri, S.; Miki, Y.; Mori, F.; Takahashi, H. The Lewy body in Parkinson's disease and related neurodegenerative disorders. Mol. Neurobiol. 2013, 47, 495-508.

(4) Eichmann, C.; Campioni, S.; Kowal, J.; Maslennikov, I.; Gerez, J.; Liu, X.; Verasdonck, J.; Nespovitaya, N.; Choe, S.; Meier, B. H.; Picotti, P.; Rizo, J.; Stahlberg, H.; Riek, R. Preparation and Characterization of Stable alpha-Synuclein Lipoprotein Particles. J. Biol. Chem. 2016, 291, 8516-27.

(5) Grey, M.; Linse, S.; Nilsson, H.; Brundin, P.; Sparr, E. Membrane interaction of $\alpha$-synuclein in different aggregation states. J. Parkinson's Dis. 2011, 1, 359-371.

(6) Hellstrand, E.; Nowacka, A.; Topgaard, D.; Linse, S.; Sparr, E. Membrane lipid coaggregation with alpha-synuclein fibrils. PLoS One 2013, 8, No. e77235.

(7) Silva, R. A. G. D.; Huang, R.; Morris, J.; Fang, J.; Gracheva, E. O.; Ren, G.; Kon- tush, A.; Jerome, W. G.; Rye, K.-A.; Davidson, W. S. Structure of apolipoprotein A-I in spherical high density lipoproteins of different sizes. Proc. Natl. Acad. Sci. U. S. A. 2008, 105, 1217612181.

(8) Sparr, E.; Engel, M. F. M.; Sakharov, D. V.; Sprong, M.; Jacobs, J.; de Kruijff, B.; Hoppener, J. W. M.; Killian, J. A. Islet amyloid polypeptide-induced membrane leakage involves uptake of lipids by forming amyloid fibers. FEBS Lett. 2004, 577, 117-120.

(9) Domanov, Y. A.; Kinnunen, P. K. J. Islet amyloid polypeptide forms rigid lipid-protein amyloid fibrils on supported phospholipid bilayers. J. Mol. Biol. 2008, 376, 42-54.

(10) Nowacka, A.; Mohr, P. C.; Norrman, J.; Martin, R. W.; Topgaard, D. Polarization transfer solid-state NMR for studying surfactant phase behavior. Langmuir 2010, 26, 16848-56.

(11) Galvagnion, C.; Buell, A. K.; Meisl, G.; Michaels, T. C. T.; Vendruscolo, M.; Knowles, T. P. J.; Dobson, C. M. Lipid vesicles trigger alpha-synuclein aggregation by stimulating primary nucleation. Nat. Chem. Biol. 2015, 11, 229-34.

(12) Galvagnion, C.; Brown, J. W. P.; Ouberai, M. M.; Flagmeier, P.; Vendruscolo, M.; Buell, A. K.; Sparr, E.; Dobson, C. M. Chemical properties of lipids strongly affect the kinetics of the membraneinduced aggregation of alpha-synuclein. Proc. Natl. Acad. Sci. U. S. A. 2016, 113, 7065-70.

(13) Buell, A. K.; Galvagnion, C.; Gaspar, R.; Sparr, E.; Vendruscolo, M.; Knowles, T. P. J.; Linse, S.; Dobson, C. M. Solution conditions determine the relative importance of nucleation and growth processes in alpha-synuclein aggregation. Proc. Natl. Acad. Sci. U. S. A. 2014, $111,7671-6$

(14) Grey, M.; Dunning, C. J.; Gaspar, R.; Grey, C.; Brundin, P.; Sparr, E.; Linse, S. Acceleration of alpha-synuclein aggregation by exosomes. J. Biol. Chem. 2015, 290, 2969-82.

(15) Brown, J. W. P.; Meisl, G.; Knowles, T. P. J.; Buell, A. K.; Dobson, C. M.; Galvagnion, C. Kinetic barriers to alpha-synuclein protofilament formation and conversion into mature fibrils. Chem. Commun. (Cambridge, U. K.) 2018, 54, 7854-7857.
(16) van der Wateren, I. M.; Knowles, T. P. J.; Buell, A. K.; Dobson, C. M.; Galvagnion, C. C-terminal truncation of $\alpha$-synuclein promotes amyloid fibril amplification at physiological pH. Chem. Sci. 2018, 9, $5506-5516$.

(17) Herzfeld, J.; Berger, A. E. Sideband intensities in NMR spectra of samples spinning at the magic angle. J. Chem. Phys. 1980, 73, 6021-6030.

(18) Hirschinger, J. A simple analytical model to describe dynamic magic-angle spinning experiments. Concepts Magn. Reson., Part A 2006, 28A, 307-320.

(19) Suwelack, D.; Rothwell, W. P.; Waugh, J. S. Slow molecular motion detected in the NMR spectra of rotating solids. J. Chem. Phys. 1980, 73, 2559-2569.

(20) Nowacka, A.; Bongartz, N. A.; Ollila, O. H. S.; Nylander, T.; Topgaard, D. Signal intensities in (1) $\mathrm{H}-(1)(3) \mathrm{C}$ CP and INEPT MAS NMR of liquid crystals. J. Magn. Reson. 2013, 230, 165-75.

(21) Ferreira, T. M.; Coreta-Gomes, F.; Ollila, O. H. S.; Moreno, M. J.; Vaz, W. L. C.; Topgaard, D. Cholesterol and POPC segmental order parameters in lipid membranes: solid state $1 \mathrm{H}-13 \mathrm{C}$ NMR and MD simulation studies. Phys. Chem. Chem. Phys. 2013, 15, 1976-89.

(22) Ferreira, T. M.; Ollila, O. H. S.; Pigliapochi, R.; Dabkowska, A. P.; Topgaard, D. Model-free estimation of the effective correlation time for $\mathrm{C}-\mathrm{H}$ bond reorientation in amphiphilic bilayers: (1) $\mathrm{H}-(13) \mathrm{C}$ solid-state NMR and MD simulations. J. Chem. Phys. 2015, 142, No. 044905.

(23) Becker, J.; Comotti, A.; Simonutti, R.; Sozzani, P.; Saalwächter, $\mathrm{K}$. Molecular motion of isolated linear alkanes in nanochannels. J. Phys. Chem. B 2005, 109, 23285-23294.

(24) Nowacka, A.; Douezan, S.; Wadsö, L.; Topgaard, D.; Sparr, E. Small polar molecules like glycerol and urea can preserve the fluidity of lipid bilayers under dry conditions. Soft Matter 2012, 8, 14821491.

(25) Earl, W. L.; VanderHart, D. L. Observations in Solid Polyethylenes by Carbon-13 Nuclear Magnetic Resonance with Magic Angle Sample Spinning. Macromolecules 1979, 12, 762-767.

(26) Batchelor, J. G.; Prestegard, J. H.; Cushley, R. J.; Lipsky, S. R. Conformational analysis of lecithin in vesicles by $13 \mathrm{C}$ NMR. Biochem. Biophys. Res. Commun. 1972, 48, 70-5.

(27) Purusottam, R. N.; Senicourt, L.; Lacapere, J.-J.; Tekely, P. Probing the gel to liquid- crystalline phase transition and relevant conformation changes in liposomes by (13)C magic-angle spinning NMR spectroscopy. Biochim. Biophys. Acta, Biomembr. 2015, 1848, 3134-9. 